\title{
PENGARUH CELEBRITY ENDORSER, SHOPPING ORIENTATION, ONLINE TRUST, DAN PRIOR ONLINE PURCHASE EXPERIENCE TERHADAP MINAT BELI KONSUMEN TOKO ONLINE ELEVENIA DI DKI JAKARTA
}

\author{
Deasi Arindani \\ Program Studi Magister Manajemen Universitas Tarumanagara \\ deasi.117172029@stu.untar.ac.id \\ Riris Loisa \\ Program Studi Magister Manajemen Universitas Tarumanagara
}

\begin{abstract}
Currently based on data from APJII the number of internet users in Indonesia reaches 143.26 million or around $54.68 \%$ and the number of e-commerce transactions reaches Rp 85 trillion in 2017, so this is a potential development of e-commerce in Indonesia. But according to data from Google Temasek research, one of the e-commerce Elevenia has been downgraded from I-4 quarter in 2017. PT XL Axiata sold Elevenia's shares and was bought by Salim Group, then their made a new strategy to increase the number of purchases. In this research, there are 4 variables that can influence buying intention : Celebrity Endorser, Shopping Orientation, Online Trust, and Prior Online Purchase Experience. This research aims to determine the effect of these four variables on Buying Intention. The method used is a quantitative method with the type of research is descriptive. Sampling method used is purposive non-probability sampling with 105 respondents. The analysis technique used is multiple linear regression analysis. This research found that celebrity endorsers, shopping orientations, online trusts, and prior online purchase experience have positive and significant influence simultaneously towards buying intention by $59 \%$, and the rest $41 \%$ is influenced by other variables not examined in this research.
\end{abstract}

Abstrak : Berdasarkan data dari APJII, saat ini jumlah pengguna internet di Indonesia mencapai sebanyak 143,26 juta jiwa atau sekitar 54,68\% dan jumlah transaksi e-commerce mencapai Rp 85 triliun pada tahun 2017, sehingga ini merupakan perkembangan potensial $e$ commerce di Indonesia. Namun menurut data dari Google temasek research, salah satu $e$ commerce yaitu Elevenia mengalami penurunan peringkat dari kuartal I-4 pada tahun 2017. PT XL Axiata menjual saham Elevenia dan dibeli oleh Salim Group kemudian melakukan upaya dengan strategi baru untuk meningkatkan jumlah pembelian. Terdapat 4 variabel yang dapat mempengaruhi minat beli dalam penelitian ini yaitu Celebrity Endorser, Shopping Orientation, Online Trust, dan Prior Online Purchase Experience. Penelitian yang bertujuan untuk mengetahui pengaruh keempat variabel tersebut terhadap Minat Beli. Metode yang digunakan adalah metode kuantitatif dengan jenis penelitian deskriptif. Pengambilan sampel menggunakan metode non-probability sampling jenis purposive sampling dengan 105 responden. Teknik analisis data menggunakan analisis regresi linier berganda. Penelitian ini menemukan bahwa celebrity endorser, shopping orientation, online trust, dan prior online purchase experience secara simultan berpengaruh positif dan signifikan terhadap minat beli sebesar 59\%, dan sisanya sebesar $41 \%$ dipengaruhi variabel lain yang tidak diteliti.

Keywords : Celebrity Endorsers, Shopping Orientations, Online Trusts, Prior Online Purchase Experience, E-commerce 


\section{PENDAHULUAN}

Pertumbuhan Ekonomi dan perkembangan Teknologi di Indonesia membuat internet menjadi salah satu media yang disukai oleh masyarakat. Menurut survei yang dilakukan oleh Asosiasi Penyelenggara Jasa Internet Indonesia (APJII, 2017), pengguna internet di Indonesia mencapai 143,26 Juta Jiwa atau sekitar 54,68\% dari total penduduk di Indonesia yang berjumlah 262 Juta Jiwa pada tahun 2017. Pertumbuhan tersebut juga didukung oleh pernyataan dari Indonesian E-commerce Association (Idea) yang menyebutkan bahwa nilai transaksi e-commerce pada tahun 2017 mencapai angka Rp 85 triliun. Data tersebut menunjukkan bahwa perkembangan e-commerce di Indonesia masih sangat potensial.

Namun salah satu toko daring Elevenia cenderung mengalami penurunan peringkat dari kuartal I-4 di tahun 2017 (Google Temasek,2017) padahal di tahun tersebut Elevenia melakukan kampanye yang cukup besar dengan menggunakan Raisa Andriana sebagai celebrity endorser. Pada bulan Agustus 2017, PT XL Axiata menjual saham Elevenia dan dibeli oleh Salim Group kemudian melakukan upaya dengan strategi baru untuk meningkatkan jumlah pembelian. Faktor-faktor yang mempengaruhi minat beli online antara lain celebrity endorser (sertoglu et al, 2014), shopping orientation, online trust, dan prior online purchase experience (Kwek et al, 2010). Penelitian ini bertujuan untuk menguji pengaruh celebrity endorser, shopping orientation, online trust, dan prior online purchase experience terhadap minat beli pada konsumen toko online Elevenia di DKI Jakarta.

\section{TINJAUAN PUSTAKA}

E-commerce merupakan satu set dinamis teknologi, aplikasi, dan proses bisnis yang menghubungkan perusahaan, konsumen, dan komunitas tertentu melalui transaksi elektronik dan perdagangan barang, pelayanan, dan informasi yang dilakukan secara elektronik (David Baum dalam Onno W. Purbo, 2000). Menurut Pavlou dalam Thamizhvanan dan Xavier (2013) minat beli online adalah "The situation when a customer is willing and intends to become involved in online transaction, where the online transaction is an activity in which the process of information retrieval, information transfer, and product purchase are taken place". Transaksi daring dapat dianggap sebagai suatu kegiatan di mana proses pencarian informasi, transfer informasi, dan pembelian produk terjadi (Pavlou dalam Thamizhvanan dan Xavier, 2013). Ajzen \& Fishbein dalam Lee \& Kotler, 2011 menegaskan dalam "theory of reasoned action" bahwa perilaku konsumen dapat diprediksikan lewat intensi mereka melalui tindakan, tujuan, dan konteks perilaku mereka.

Terence A. Shimp (2003) mendefinisikan endorser adalah pendukung iklan atau biasa dikenal sebagai bintang iklan yang mendukung produk yang diiklankan. Sedangkan celebrity adalah tokoh (aktor, penghibur atau atlet) yang dikenal karena prestasinya dalam bidangbidang yang berbeda dari produk yang didukungnya. Celebrity Endorser adalah menggunakan artis sebagai bintang iklan di media - media, mulai dari media cetak, televisi, radio, maupun media sosial. Shimp (2007) menyatakan bahwa "Extensive reaserch has demonstrated that two general attributes, credibility and actractiveness, contribute to an endorser's effectiveness and that each consists of more distinct subatribute. We use the acronym TEARS to represent five discrete attributes: trustworthiness and expertise are two dimensions of credibility, whereas phsycal attractiveness, respect and similarity (to target audience) are components of the general concept of attractiveness".

$\mathrm{H}_{1}$ : Terdapat pengaruh yang signifikan celebrity endorser terhadap minat beli

Ling, et al (2010:5) menyatakan Orientasi belanja merupakan bagian tertentu dari gaya hidup dan dijalankan oleh berbagai kegiatan, kepentingan dan pernyataan pendapat yang relevan dengan tindakan belanja. Dimensinya yaitu Orientasi Belanja Impulsif, Orientasi Belanja berdasarkan Kualitas, dan Orientasi Belanja berdasarkan Merek.

$\mathrm{H} 2$ : Terdapat pengaruh yang signifikan shopping orientation terhadap minat beli 
Menurut Kimery dan McCard (2002, dalam Ling et al., 2010), kepercayaan online adalah kesediaan pelanggan untuk menerima kelemahan dalam transaksi daring berdasarkan harapan positif mereka mengenai perilaku belanja daring di masa yang akan datang. Terdapat 3 dimensi kepercayaan daring, yaitu Security, Privacy, dan Company Reability.

H3 : Terdapat pengaruh yang signifikan online trust terhadap minat beli

Dalam teori perilaku konsumen menurut Kotler dan Keller (2012:185), pembelajaran mendorong perubahan dalam perilaku seseorang yang timbul dari pengalaman. Menurut Thamizhvanan dan Xavier (2013), perilaku di masa yang akan datang ditentukan oleh pengalaman sebelumnya. Dalam lingkungan belanja daring, pengalaman pembelian daring sebelumnya mengarah pada pengurangan ketidakpastian dan akhirnya menyebabkan peningkatan dalam minat beli konsumen (Shim dan Drake, 1990, dalam Thamizhvanan dan Xavier, 2013).

H4 : Terdapat pengaruh yang signifikan prior online purchase experience terhadap minat beli H5 : Terdapat pengaruh yang signifikan celebrity endorser, shopping orientation, online trust, dan prior online purchase experience secara simultan terhadap minat beli

\section{METODE PENELITIAN}

Metode penelitian yang digunakan adalah penelitian kuantitatif-deskriptif. Ada dua macam variabel yang digunakan dalam penelitian ini yaitu variabel bebas (celebrity endorser, shopping orientation, online trust, dan prior online purchase experience) dan variabel terikat (dalam hal ini adalah purchase intention). Populasi dalam penelitian ini adalah konsumen toko daring Elevenia yang berlokasi di wilayah DKI Jakarta. Teknik pengambilan sampel adalah Non Probability Sampling yaitu teknik purposive sampling, yaitu pernah melakukan pembelian pada toko daring Elevenia minimal 1 (satu) kali dan berlokasi di wilayah DKI Jakarta. Jumlah sampel dalam penelitian ini adalah 105 responden.

Pernyataan untuk variabel bebas (celebrity endorser, shopping orientation, online trust, prior online purchase experience) dan variabel terikat (purchase intention) terdiri atas 26 item pernyataan. Uji validitas terhadap pernyataan-pernyataan tersebut menggunakan SPSS 23.00 dan semua butir valid karena memenuhi syarat memiliki total nilai sig. 2 tailed lebih kecil dari 0,05 dan total nilai pearson's correlation positif. Hasil uji reliabilitas seluruh variabel memiliki nilai koefisien cronbach's alpha lebih dari 0,60 maka dapat disimpulkan bahwa semua butir pertanyaan reliabel.

\section{HASIL PENELITIAN}

Dari hasil analisa deskriptif, jumlah responden wanita $(74.3 \%)$ lebih tinggi dibandingkan responden laki-laki $(25.7 \%)$. Terdapat berbagai pertimbangan yang mendorong responden wanita melakukan pembelian di toko online diantaranya adalah banyaknya pilihan barang dan kemungkinan harga lebih rendah juga bisa menjadi alasan bagi responden wanita tertarik melakukan pembelian secara online. Selanjutnya usia 20-25 tahun merupakan responden dengan jumlah paling banyak yaitu sebesar 66 (62.9\%). Responden usia ini memiliki kecenderungan aktif untuk mencoba berbagai hal baru termasuk pembelian secara online. Responden dengan pekerjaan sebagai pegawai swasta juga memiliki jumlah tertinggi yaitu 82 (78.1\%), kemudian responden dengan latar belakang pendidikan S1/Sederajat juga paling tinggi dengan jumlah 79 (75.2\%) dan responden yang memiliki pengeluaran $<\mathrm{Rp} 1.000 .000$,/bulan untuk berbelanja merupakan jumlah responden tertinggi dengan jumlah 64 (61\%). 
Berikut hasil uji analisis regresi linier berganda pada penelitian ini :

\begin{tabular}{|c|c|c|c|c|c|c|c|c|c|}
\hline \multicolumn{10}{|c|}{ Coefficients $^{\mathrm{a}}$} \\
\hline & \multirow[t]{2}{*}{ Model } & \multicolumn{2}{|c|}{$\begin{array}{l}\text { Unstandardized } \\
\text { Coefficients }\end{array}$} & \multirow{2}{*}{$\begin{array}{c}\begin{array}{c}\text { Standardized } \\
\text { Coefficients }\end{array} \\
\text { Beta } \\
\end{array}$} & \multirow[t]{2}{*}{$\mathrm{t}$} & \multirow[t]{2}{*}{ Sig. } & \multirow{2}{*}{$\begin{array}{l}\text { Adjusted } \\
\mathrm{R} \text { Square }\end{array}$} & \multirow[t]{2}{*}{$\mathrm{F}$} & \multirow{2}{*}{ Sig. } \\
\hline & & $\mathrm{B}$ & Std. Error & & & & & & \\
\hline & (Constant) & -8.317 & 4.558 & & -1.825 & .071 & \multirow{5}{*}{.590} & \multirow{5}{*}{38.339} & \multirow{5}{*}{$.000 a$} \\
\hline & TOTAL CE & .250 & .055 & .395 & 4.506 & .000 & & & \\
\hline 1 & TOTAL SO & 292 & .122 & .166 & 2.386 & .019 & & & \\
\hline & TOTALOT & .004 & .059 & .005 & .071 & .944 & & & \\
\hline & TOTALPE & .403 & .099 & .362 & 4.073 & .000 & & & \\
\hline
\end{tabular}

Tabel 4.1 Tabel hasil Uji Analisis Regresi Linier Berganda

Dari tabel 4.1, berikut hasil pengujian hipotesis yang telah dilakukan :

\begin{tabular}{|c|c|c|c|c|}
\hline No & & Hipotesis & Pengambilan keputusan & Hasil \\
\hline 1 & $\begin{array}{l}\mathrm{H}_{\circ}: \\
\mathrm{Ha}:\end{array}$ & $\begin{array}{l}\text { (tidak terdapat pengaruh yang signifikan Celebrity Endorser terhadap Purchase Intention) } \\
\text { (terdapat pengaruh yang signifikan Celebrity Endorser terhadap Purchase Intention) }\end{array}$ & $p$ value sebesar $0.00<0.05$ & $\mathrm{H}_{\mathrm{o}}$ ditolak \\
\hline 2 & Ha: & $\begin{array}{l}\text { (tidak terdapat pengaruh yang signifikan Shopping Orientation terhadap Purchase Intention) } \\
\text { (terdapat pengaruh yang signifikan Shopping Orientation terhadap Purchase Intention) }\end{array}$ & $p$ value sebesar $0.019<0.05$ & $\mathrm{H}_{\mathrm{o}}$ ditolak \\
\hline 3 & $\begin{array}{l}\mathrm{H}_{\mathrm{o}}: \\
\mathrm{Ha}:\end{array}$ & $\begin{array}{l}\text { (tidak terdapat pengaruh yang signifikan Online Trust terhadap Purchase Intention) } \\
\text { (terdapat pengaruh yang signifikan Online Trust terhadap Purchase Intention) }\end{array}$ & $p$ value sebesar $0.944>0.05$ & $\mathrm{H}_{\mathrm{o}}$ tidak ditolak \\
\hline 4 & $\begin{array}{l}\mathrm{H}_{\circ}: \\
\mathrm{Ha}:\end{array}$ & $\begin{array}{l}\text { (tidak terdapat pengaruh yang signifikan Prior Online Purchase Experience terhadap Purchase } \\
\text { Intention) } \\
\text { (terdapat pengaruh yang signifikan Prior Online Purchase Experience terhadap Purchase } \\
\text { Intention) }\end{array}$ & P value sebesar $0.00>0.05$ & $\mathrm{H}_{\mathrm{o}}$ ditolak \\
\hline 4 & $\mathrm{Ha}$ & $\begin{array}{l}\text { (Tidak terdapat pengaruh yang signifikan Celebrity Endorser, Shopping Orientation, Online } \\
\text { Trust, dan Prior Online Purchase Experience secara simultan terhadap Purchase Intention) } \\
\text { (Paling sedikit ada satu Variable X (Celebrity Endorser, Shopping Orientation, Online Trust, } \\
\text { dan Prior Online Purchase Experience) yang mempengaruhi variable Y (Purchase Intention) }\end{array}$ & $P$ value sebesar $0.00<0.05$ & $\mathrm{H}_{0}$ ditolak \\
\hline
\end{tabular}

Tabel 4.2 Tabel Uji Hipotesis

Sehingga dapat disimpulkan model persamaan regresi sebagai berikut :

$\mathrm{Y}=-\mathbf{8 . 3 1 7}+0.250 \mathrm{X} 1+0.292 \mathrm{X} 2+0.004 \mathrm{X3}+0.403 \mathrm{X} 4+\mathrm{e}$

Kesimpulan :

- Celebrity Endorser mempunyai pengaruh yang positif dan signifikan terhadap minat beli konsumen online sebesar 0.250 . Hal ini menyatakan bahwa setiap penambahan 1 (satu) satuan variabel Celebrity Endorser akan meningkatkan Minat Beli konsumen online sebesar 0.250 .

- Shopping Orientation mempunyai pengaruh yang positif dan signifikan terhadap Minat Beli konsumen Online sebesar 0.292. Hal ini menyatakan bahwa setiap penambahan 1 (satu) satuan variabel Shopping Orientation akan meningkatkan Minat Beli konsumen online sebesar 0.292 .

- Kepercayaan Online memiliki pengaruh yang positif namun tidak signifikan terhadap Minat Beli konsumen Online sebesar 0.004, berarti setiap penambahan 1 (satu) satuan variabel Kepercayaan Online akan meningkatkan Minat Beli konsumen online sebesar 0.004 .

- Pengalaman Pembelian Online memiliki pengaruh yang positif dan signifikan terhadap Minat Beli konsumen Online sebesar 0.403. Hal ini menyatakan bahwa setiap 
penambahan 1 (satu) satuan variabel Pengalaman Berbelanja Online akan meningkatkan Minat Beli konsumen online sebesar 0.403.

- Celebrity Endorser, Shopping Orientation, Online Trust, dan Prior Online Purchase Experience memiliki pengaruh yang positif dan signifikan secara simultan terhadap Minat Beli konsumen Online sebesar 0.59. Artinya sebesar 59\% dari variable Y (Purchase Intention) dapat dijelaskan oleh variable X (Celebrity Endorser, Shopping Orientation, Online Trust, dan Prior Online Purchase Experience), sedangkan sisanya sebesar $41 \%$ dijelaskan oleh variabel lainnya diluar penelitian ini.

\section{SARAN}

Berdasarkan pada hasil penelitian yang telah dilakukan dapat dilihat bahwa toko daring sebaiknya memformulasikan dan mengimplementasikan berbagai strategi bisnis untuk meningkatkan minat beli pada konsumen, khususnya toko daring Elevenia dalam penelitian ini. Toko daring sebaiknya selektif dalam memilih selebriti yang digunakan sebagai endorser, terutama selebriti tersebut harus memiliki aspek tiga dimensi (daya tarik, keahlian, dan kepercayaan) dan sesuai dengan produk yang didukungnya. Selain itu, harus diperhatikan juga bahwa selebriti tersebut lebih baik tidak terlalu banyak mendukung produk lainnya namun memiliki target audience yang sesuai. Selanjutnya untuk meningkatkan Shopping Orientation dapat dilakukan dengan cara memberikan promosi potongan harga, gratis biaya pengiriman, flash sale, menjual produk eksklusif atau produk baru, memberikan jaminan barang original, memberikan garansi produk dan pengiriman, membentuk komunitas konsumen daring, sistem membership dan poin untuk keanggotaan eksklusif, serta selalu memberikan informasi produk yang lengkap dan berkualitas. Kemudian untuk meningkatkan Online Trust dapat dilakukan dengan cara meningkatkan sistem keamanan dan kerahasiaan dalam bertransaksi, selalu memberikan tanggapan yang baik terhadap keluhan para konsumen, kebijakan penukaran barang dan garansi yang lebih terjamin, serta menampilkan review dan testimonial mengenai produk tersebut dari para pembeli yang lalu. Sedangkan dalam meningkatkan Prior Online Purchase Experience dapat dilakukan dengan cara memberikan layanan konsumen untuk mengutarakan masukan mengenai produk dan layanan, selalu mengirimkan barang tepat waktu dan dalam kondisi yang baik, memberikan hadiah atau souvenir kepada konsumen dengan minimal pembelian tertentu, serta selalu mempermudah cara berbelanja agar konsumen nyaman dalam berbelanja.

Akhir kata seperti yang di ungkapkan sebelumnya bahwa banyak hal yang dapat memberikan pengaruh bagi Minat Beli konsumen daring, maka penulis berharap penelitian ini dapat menjadi acuan bagi penelitian-penelitan selanjutnya dan dapat menjadi dasar pengembangan penelitian terhadap toko daring lainnya serta konsumen potensial yang memiliki minat yang besar terhadap berbelanja secara daring. Selain itu penelitian selanjutnya juga dapat menguji pengaruh antara Celebrity Endorser terhadap Minat Beli yang dimediasi oleh sikap dan Orientasi Belanja, Minat Beli yang dimediasi oleh Gender, kemudian mencari hubungan antara intensitas pengalaman berbelanja terhadap tujuan berbelanja secara daring pada masa yang akan datang, serta memperluas skala geografis pengambilan sampel. 


\section{DAFTAR PUSTAKA}

Asosiasi Penyelenggara Jasa Internet Indonesia (APJII). 2017. Profil Pengguna Internet Indonesia.

https://web.kominfo.go.id/sites/default/files/Laporan\%20Survei\%20APJII_2017_v1.3. pdf diakses pada April 2018. Jakarta: Asosiasi Penyelenggara Jasa Internet Indonesia.

Brown, M., Pope, N. Voges, K. (2003). Buying or Browsing? : An exploration of Shopping Orientation and Online Purchase Intention. European Journal of Marketing. 37. 16661684

Delafrooz. (2011). Understanding consumer's internet purchase intention in Malaysia. International journal of business management, Vol. 5(3), pp.2837-2846

Gehrt, K.C., Onzo, N., Fujita, K. and Rajan, N.R. (2007). The emergence of internet shopping in Japan: identification of shopping orientation-defined segment. Journal of Marketing Theory and Practice, 15(2), 167-177

Ghozali, I. (2005). Aplikasi Analisis Multivariate dengan program SPSS. Semarang: Badan Penerbit Universitas Diponegoro

Group, iPrice. (2017). Persaingan e-commerce Indonesia di 2017, siapa terpopuler? https://inet.detik.com/telecommunication/d-3620332/bos-xl-blak-blakan-kenapamelepas-elevenia diakses pada April 2018.

Kotler, Philip. (2000). Marketing Management Millenium Edition, Tenth Edition. Pearson Custom Publishing, Boston. Kotler \& Armstrong. (2010). Principles of Marketing. Pearson Prentice Hall, New York.

Kuncoro, M. (2007). Metode Kuantitatif, Teori dan Aplikasi untuk Bisnis dan Ekonomi, Yogyakarta: UPP STIM YKP

Ling, Kwek Choon., Lau, Teck. Chai, Hoi, Tan Piew. (2010). Investigating the Shopping Orientations on Online Purchase Intention in the e-Commerce Environment: A Malaysian Study. Journal of Internet Banking and Commerce, August, Vol.15, No.2.

Ling, Kwek Choon., Lau, Teck. Chai, Hoi, Tan Piew. (2010). The Effects of Shopping Orientation, Online Trust and Prior Online Purchase Experience toward Customers' Online Purchase Intention. International Business Reseach. 3 (3). 63-74

Rook, D.W. (1987). The buying impulse. Journal of Consumer Research, 14(2), 189-1999

Rosalina, Dessy. (2017). Sah, XL Axiata resmi jual seluruh saham Elevenia. Diakses pada April 2018. https://investasi.kontan.co.id/news/sah-xl-axiata-resmi-jual-seluruh-sahamelevenia.

Rizan, Mohamad dkk. (2015). The relationship between customer satisfaction and security toward trust and its impact on repurchase intention (survey on customer of elevenia online website). Jurnal Riset Manajemen Sains Indonesia (JRMSI) vol. 6 no. 2

Sekaran, Uma. (2006). Metodologi Penelitian untuk Bisnis, Edisi 4, Buku 1, Jakarta: Salemba Empat

Sekaran, Uma. (2006). Metodologi Penelitian untuk Bisnis, Edisi 4, Buku 2, Jakarta: Salemba Empat

Shimp T. 2007. Integrated Marketing Communication In Advertising \& Promotion Seventh Edition. International Student Edition. New York (US): McGrawHill. 